\title{
LEGIONELLA PREVALENCE AND RISK OF LEGIONELLOSIS IN HUNGARIAN HOSPITALS
}

\author{
ZSÓFIA BARNA, MiHÁly KÁdÁR, EMESE KÁlmÁn, EsZTER RÓKA, \\ ANITA SCH. SZAX and MÁRTA VARGHA* \\ National Public Health Center, Directoriate of Environmental Health, Albert Flórián út 2-6, \\ H-1097 Budapest, Hungary
}

(Received: 13 August 2015; accepted: 19 October 2015)

\begin{abstract}
Nosocomial legionellosis is a growing concern worldwide. In Hungary, about $20 \%$ of the reported cases are health-care associated, but in the absence of legal regulation, environmental monitoring of Legionella is not routinely performed in hospitals. In the present study, 23 hospitals were investigated. The hot water distribution system was colonized by Legionella in over $90 \%$; counts generally exceeded the public health limit value. Hot water temperature was critically low in all systems $\left(<45{ }^{\circ} \mathrm{C}\right)$, and large differences $\left(3-38{ }^{\circ} \mathrm{C}\right.$ temperature drop) were observed within buildings, indicating insufficient circulation. Most facilities were older than 30 years $(77 \%)$; however, new systems $(n=3)$ were also shown to be rapidly colonized at low hot water temperature. Vulnerable source of drinking water, complex distribution system, and large volume hot water storage increased the risk of Legionella prevalence $(\mathrm{OR}=28.0,27.3,27.7$, respectively). Risk management interventions (including thermal or chemical disinfection) were only efficient if the system operation was optimized. Though the risk factors were similar, in those hospitals where nosocomial legionellosis was reported, Legionella counts and the proportion of L. pneumophila sg 1 isolates were significantly higher. The results of environmental prevalence of legionellae in hospitals suggest that the incidence of nosocomial legionellosis is likely to be underreported. The observed colonization rates call for the introduction of a mandatory environmental monitoring scheme.
\end{abstract}

Keywords: hospital acquired legionnaires' disease, Hungary, Legionella spp., risk assessment

\section{Introduction}

Nosocomial legionellosis is a growing concern worldwide. It was reported to be responsible for up to $14 \%$ of all health-care associated pneumonia cases [1].

*Corresponding author; E-mail: vargha.marta@oki.antsz.hu 
In countries with higher awareness of Legionella, risk management plan and preventive measures are implemented in the hospitals. Some regulations rely solely on clinical surveillance, while others require environmental monitoring as well. Consequently, Legionella alert is either given on the incidence of nosocomial legionellosis or at a certain level of colonization [2]. The latter is usually defined as a combination of high ratio of positive samples, and a colony count limit value of the individual samples. The limit of intervention is variable in different countries, but the most widely accepted value for hot water systems is 1000 colony forming unit (CFU)/L [3-6]. All health care facilities are considered high-risk areas due to the susceptibility of the exposed population, and the high mortality of nosocomial legionellosis (30\%) [7, 8]. Some wards (e.g. intensive care units, oncology, haematology, transplantation or dialysis) are considered even more sensitive, and therefore stricter limit values may apply [0 CFU/L - 250 CFU/L depending on the national regulations] [5].

In Hungary, there is currently no regulation for environmental monitoring of Legionella in hospitals. The clinical surveillance system is active and includes legionellosis as a mandatory reportable disease. However, due to the low general awareness, the diagnostic tests are seldom directed towards Legionella. As a consequence, legionellosis is presumably largely underdiagnosed and underreported in Hungary. The number of reported cases between 2009 and 2013 was $4.5 /$ year/million inhabitants on average, $18 \%$ of which were nosocomial (confirmed or presumed) [9]. This value is considerably lower than the EU average (11.4 cases/million inhabitants, including 5\% nosocomial) [9].

The largest recognized health-care associated Legionella infections were linked to the cooling towers on the premises of the hospitals [10]. Though cooling towers are still a concern, the potable or hot water distribution system is also considered to be a major source of infection [11-18]. However, there is seemingly no direct correlation between the Legionella sp. counts and the number of detected legionellosis cases [18]. Other factors, such as the species and serotype distribution - and in effect the virulence - of the strains present in the water distribution system or other potential source also influence the prevalence of infections. Although numerous parameters such as water temperature, pipe materials, flow circumstances, stagnation, pipe corrosion, some trace elements and the presence or absence of some other microorganisms are well-known factors favouring the growth of Legionellaceae, it is unclear what determines the prevalence of certain taxa [19-23]. The presence of hazardous exposure routes, e.g. aerators or humidifiers using tap water or aerating tap faucets and showerheads also enhances the risk of infection, as well as the immunostatus of the patients $[8,24]$. 
In the absence of monitoring, there was no previous data on the colonization rates of the hospitals in Hungary.

In the present study, 23 Hungarian hospitals of various geographic locations were surveyed. Some of the hospitals (14) reported at least one nosocomial legionellosis case. The hospitals were compared with respect to the level of Legionella colonization, the presence of presumably virulent serotypes, architectural engineering characteristics. The aim was to assess the contribution of the various factors in rate of colonization in hospitals and the prevalence of recognized legionellosis cases.

\section{Materials and Methods}

\section{Study sites}

Twenty-three hospitals were surveyed by on-site investigation and water sampling (Table I). A standardized questionnaire was used to identify all potential risk sources. The questionnaire covered a wide range of water environments, such as wet cooling towers, hydrotherapy pools, humidifiers or air conditioning, indoor or outdoor decorative fountains, stored water for fire-fighting systems, sprinklers, etc. However, answers were uniformly negative in all facilities, and accordingly subsequent investigation was focused on the potable and hot water distribution system. One hospital had two separate hot water systems, thus overall 24 systems were characterized for Legionella colonization. Information on the building (age, size, complexity), potable water (source, storage, treatment), hot water production (primary heat source, storage conditions, preset temperature, recirculation) was also recorded during the site visit.

\section{Sample collection}

During the study period, 799 samples were taken from 23 hospitals' hot $(n=636)$ and cold $(n=163)$ water supplies. The sampling scheme within buildings (targeting hot water storage tanks, return loops and distal outlets, including showerheads and taps) was designed to represent the entire distribution system according the EWGLI Guidelines [25]. If the sampling was performed after the hospital reported nosocomial legionellosis cases, the water outlets in the patients' room were also sampled [2]. 


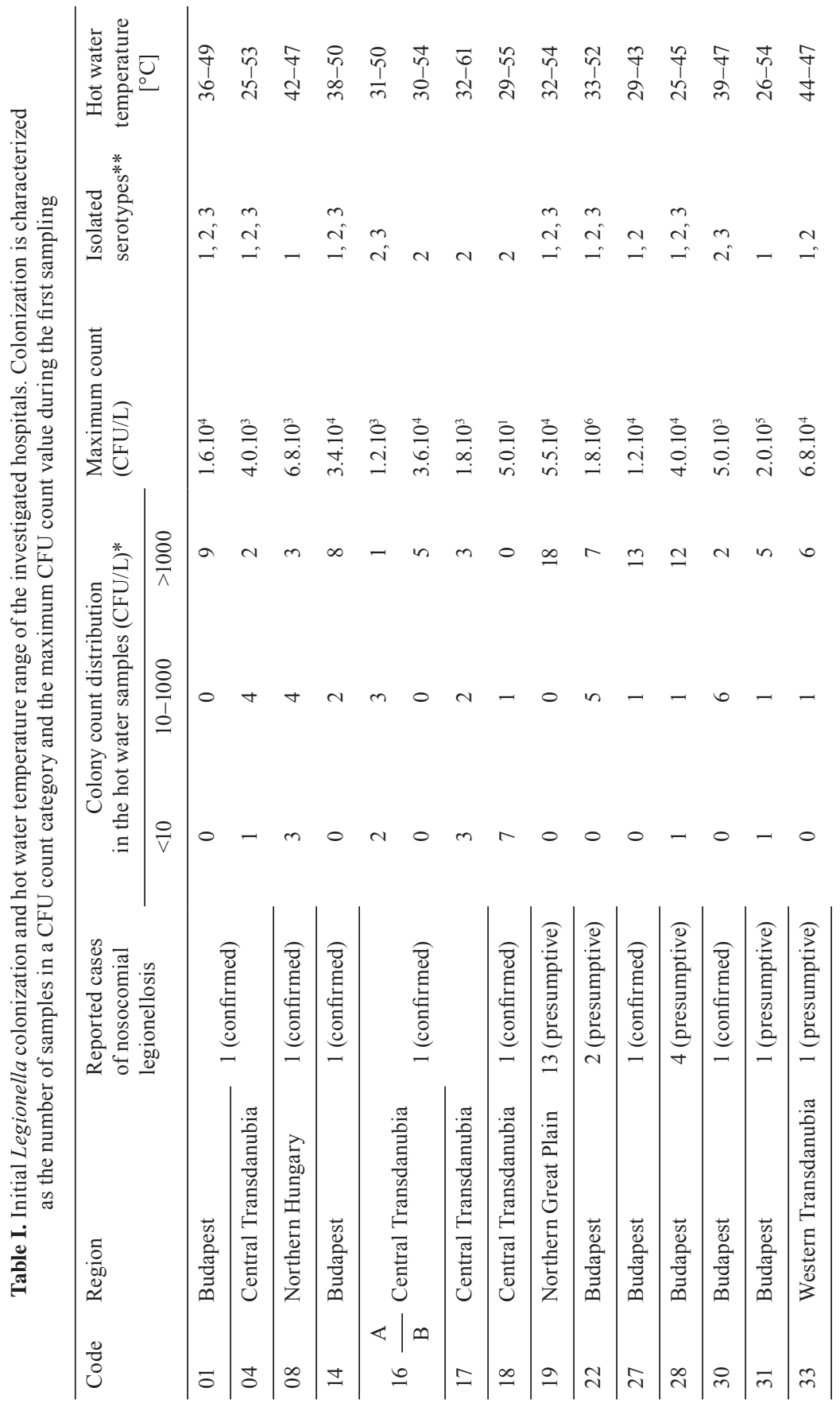




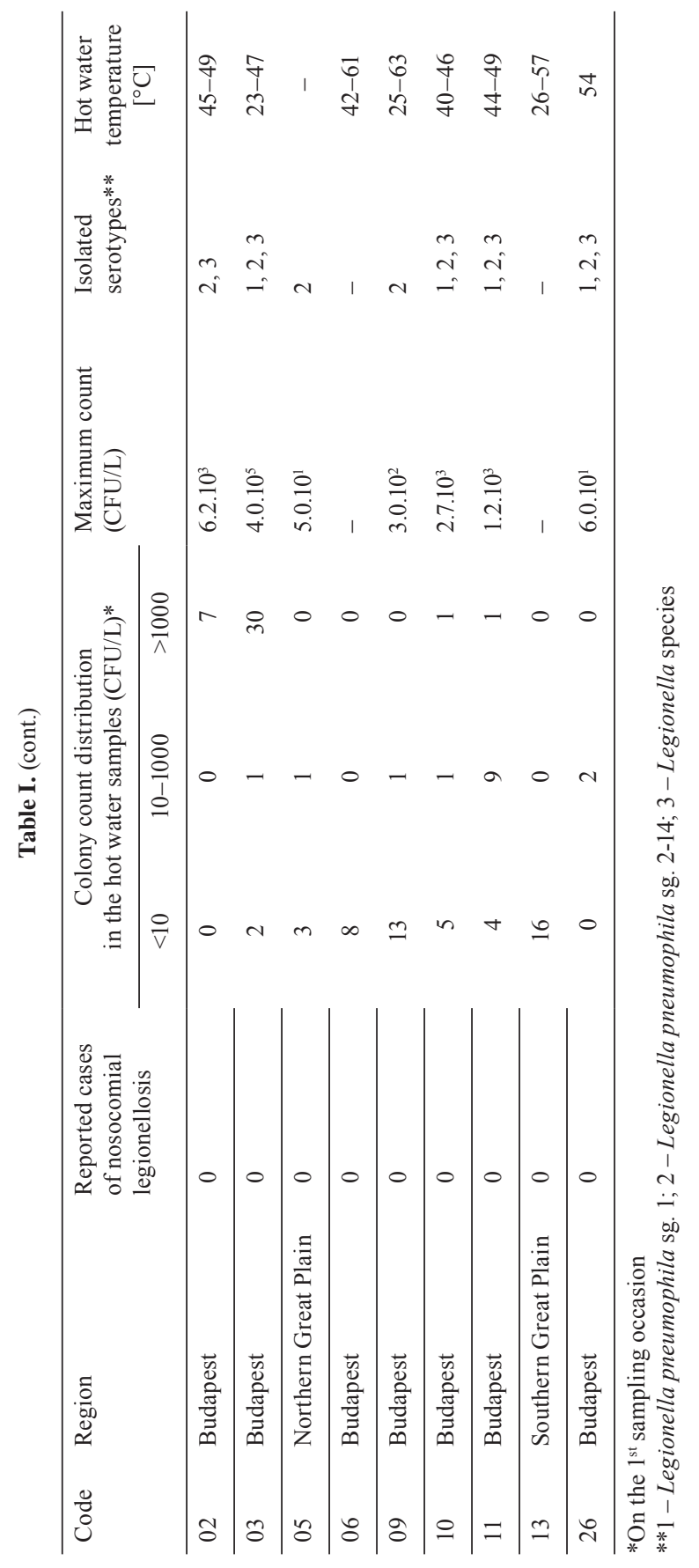


Water samples were collected according to the standards ISO 5667-5:2006 [26] and ISO 19458:2006 [27] without flaming after 1 min flushing in sterile bottles with $0.1 \% \mathrm{Na}_{2} \mathrm{~S}_{2} \mathrm{O}_{3}$ to neutralise residual free chlorine and transported immediately to the laboratory. Water temperatures were measured with an electronic calibrated thermometer (testo-735, Testo Ltd., Lenzkirch, Germany).

\section{Microbiological analysis}

The water samples were analysed for Legionella sp. by standard culture technique according to ISO 11731-2:2004 [28] briefly as follows: $100 \mathrm{~mL}$ aliquot was filtered on a $0.45 \mu \mathrm{m}$ pore size black cellulose nitrate membrane (Sartorius Stedim Biotech Ltd., Göttingen, Germany). A five-minute acid wash ( $\mathrm{pH} 2.2)$ was applied to the filters to suppress background microbiota. Legionella sp. was cultured on GVPC (Oxoid Ltd., Basingstoke, Hampshire, UK) at $36 \pm 2{ }^{\circ} \mathrm{C}$ for 10 days and read on days 3,5 and 10 under a dissecting microscope. Presumptive Legionella colonies were subcultured on BCYE with and without cysteine (Oxoid Ltd., Basingstoke, Hampshire, UK) to test for cysteine auxotrophy; the cultures were incubated at $36 \pm 1{ }^{\circ} \mathrm{C}$ for 2 days. Presumptive legionellae were identified by seroagglutination (Legionella latex test, Oxoid Ltd., Basingstoke, Hampshire, UK). The test allows the identification of L. pneumophila serogroup 1 and 2-14 and detection of seven species of non-pneumophila legionellae. Counts are given as the number of colony forming units (CFU) per $1 \mathrm{~L}$ of the water, so the detection limit of the method was $10 \mathrm{CFU} / \mathrm{L}$.

\section{Data management and statistical analysis}

Only well-characterized hot water systems were included in the analysis, where samples from multiple representative points were available. Some systems were sampled repeatedly, in this cases only the samples from the first sampling were included in the analysis of prevalence ( 289 hot and 79 cold cold water samples). Taps fitted with point-of-use bacterium filters were excluded $(n=2)$.

Systems on the first sampling occasion were sampled under normal operating condition; targeted interventions to reduce Legionella colonization - if necessary - were only performed after the first postitive results. The subsequent sampling results were considered post-intervention $(n=347)$.

Statistical analysis was performed using SPSS (SPSS Inc., Chicago, Il., USA). When possible, variables were categorized dichotomically. Mann-Whitney (MW) and Kruskal-Wallis (KW) test were performed to compare the mean values of Legionella counts in connection with the measured variables. The sero- 
type distribution of the isolated Legionella strains was assessed using $\mathrm{Chi}^{2}$ test. Odds ratios (OR) with 95\% confidence intervals (CI) were calculated to compare the proportions of contamination with respect to the measured variables. Variables that were significant and quasi-symmetric in the univariate analysis or strongly significant in MW were entered in a multiple logistic regression model.

\section{Results}

\section{Legionella colonization}

Legionella spp. was isolated from the hot water system of $92 \%$ of the investigated hospitals, only two systems were not colonized (Hospital nr. 6 and 13) (Table I). In 18 hospitals, over half of the samples were positive; Legionella counts exceeded the public health intervention value of $1000 \mathrm{CFU} / \mathrm{L}$ in $75 \%$ of the systems, thus indicating extensive colonization (Figure 1). In $29 \%$ of the hospitals the maximum value was over the limit of immediate intervention $\left(10^{4}\right.$ CFU/L).

On the first sampling occasion, $70 \%$ of the hot water samples $(n=286)$ and $38 \%$ of the cold water samples $(n=78)$ were positive (median 1.2.10 $\mathrm{CFU} / \mathrm{L}$ and

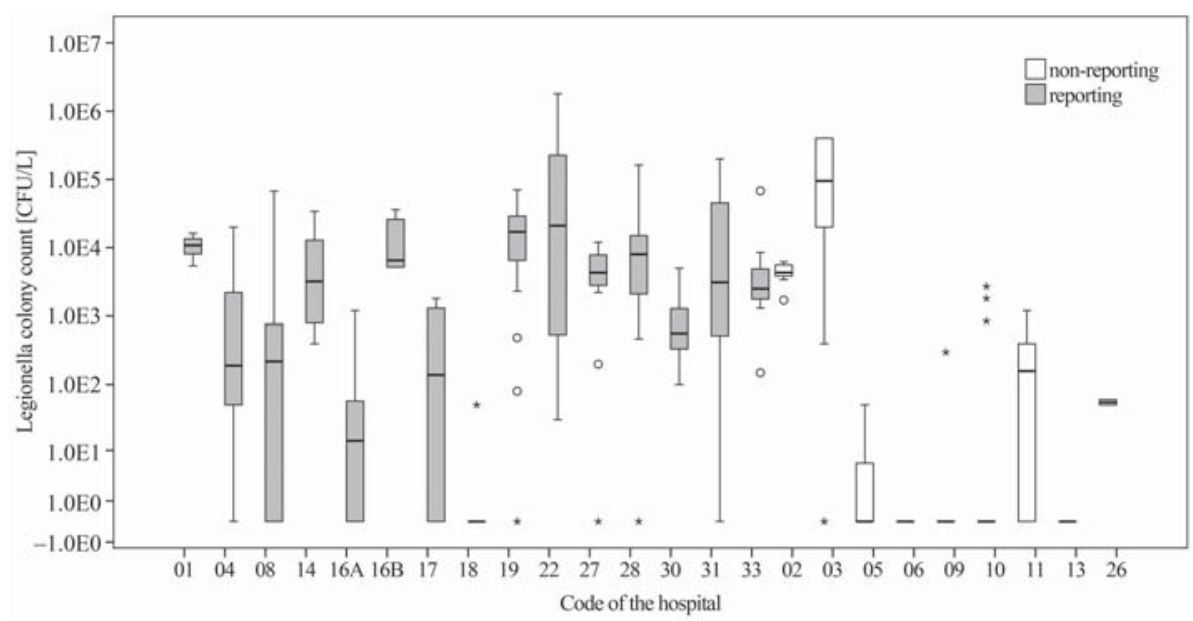

Figure 1. Legionella CFU counts detected in the hot water samples of the hospitals on the first sampling occasion. The box indicates the upper and lower quartiles, with median shown as a black line. Error bars show the minimum and maximum value (excluding outliers).

Sample numbers by facility: $\mathrm{n}_{01}=9, \mathrm{n}_{02}=7, \mathrm{n}_{03}=33, \mathrm{n}_{04}=10, \mathrm{n}_{05}=4, \mathrm{n}_{06}=8, \mathrm{n}_{08}=15$, $\mathrm{n}_{09}=14, \mathrm{n}_{10}=14, \mathrm{n}_{11}=14, \mathrm{n}_{13}=16, \mathrm{n}_{14}=12, \mathrm{n}_{16 \mathrm{~A}}=8, \mathrm{n}_{16 \mathrm{~B}}=5, \mathrm{n}_{17}=10, \mathrm{n}_{18}=12, \mathrm{n}_{19}=26, \mathrm{n}_{22}=11, \mathrm{n}_{26}=2$, $\mathrm{n}_{27}=17, \mathrm{n}_{28}=17, \mathrm{n}_{30}=8, \mathrm{n}_{31}=7, \mathrm{n}_{33}=7, \mathrm{n}_{\text {total }}=286$ 
$0(<10)$ CFU/L, respectively). Legionella counts were significantly lower in cold water; the limit value was exceeded in $51 \%$ of the hot and $6 \%$ of the cold water samples. The maximum observed values were over $10^{6} \mathrm{CFU} / \mathrm{L}$ in both hot and cold water systems. In the supplied potable water, where sampling was possible, Legionella counts were below the limit of detection. Hot water storage tanks $(\mathrm{n}=15)$ were colonized in $60 \%$, counts exceeded $1000 \mathrm{CFU} / \mathrm{L}$ in $30 \%$.

Hot water samples taken in high risk points, such as intensive care, haematology or solid organ transplant units $(n=103)$ were similar from other hospital samples $(n=183)$ : $66 \%$ was positive for Legionella. Median CFU counts were not different either (1300 and $1070 \mathrm{CFU} / \mathrm{L}$ in high risk and other samples, respectively, MW $\mathrm{p}=0.797)$.

L. pneumophila was the most prevalent species in the hot water samples. The most virulent serotype, L. pneumophila sg 1 was isolated from one third of the positive samples (87/201). Other serotypes (L. pneumophila 2-14) were detected in 69\%. Non-pneumophila species (not identified further) were present in $23 \%$ of the samples. Generally more than one type colonized a distribution system. In cold water samples, the distribution of L. pneumophila sg 1, 2-14 and L. species was similar to the hot water samples.

\section{Influencing factors}

Water temperature

On the first sampling occasion, temperature of the flushed hot water samples $(\mathrm{n}=210)$ was critically low, median temperature was $44{ }^{\circ} \mathrm{C}$, and even the upper quartile was under $50{ }^{\circ} \mathrm{C}\left(49^{\circ} \mathrm{C}\right)$. Only $4 \%$ of the samples reached the internationally recommended safe value of $55^{\circ} \mathrm{C}$. Over $55^{\circ} \mathrm{C}$, only one sample was positive for Legionella (20 CFU/L, n =9), while under $55^{\circ} \mathrm{C}$ Legionella was detected in $75 \%$ of the samples, and in $59 \%$ CFU counts exceeded the public health limit value. The difference was significant $(O R=23.5, p=0.003)$. Since in most hospitals even the set temperature of the boilers was below $55^{\circ} \mathrm{C}$, and only a fraction of the samples exceeded this value, the potential protective effect of temperatures over $50{ }^{\circ} \mathrm{C}$ was also assessed. It was confirmed to reduce colonization rates $(\mathrm{OR}=6.9, \mathrm{p}=0.0001)$.

Hot water temperature of the point of use outlets depends on the temperature of the produced water (initial temperature), and the temperature drop within the system. In the majority of the investigated hospitals, the initial temperature was lower than $60{ }^{\circ} \mathrm{C}$, only 3 systems reached this value. The temperature drop 
within the hot water distribution (difference between the initial temperature and the temperature at the distant outlets) was over $10{ }^{\circ} \mathrm{C}$ in $75 \%$ of the buildings, indicating low efficiency of water circulation and the presence of stagnant water in the distribution system. In 2 hospitals the temperature difference was extreme (over $30{ }^{\circ} \mathrm{C}$ ).

Cold water temperature was over $20^{\circ} \mathrm{C}$ in five hospitals, and over $30{ }^{\circ} \mathrm{C}$ in two. In one hospital (Nr. 31), the hot and cold water temperature was identical $\left(30-32{ }^{\circ} \mathrm{C}\right)$ in one wing of the building. The investigation revealed that during a recent reconstruction the potable and hot water sytem was inadvertently interconnected.

\section{Engineering aspects}

Building characteristics are generally presumed to influence the colonization of the water system. In the present study, age of the building and the distribution pipelines, building size (number of storeys) complexity of the buildings sharing a single hot water system (one building/more building, location of the boiler room - inside or outside the sampled building - were assessed.

Majority of the investigated hospitals (17/22) was more than 30 years old, $40 \%$ was built before 1950 (Table II). Contrary to the expected and previous results, both the rate of Legionella positive samples and the median Legionella counts were higher in the newer facilities (built after 2000) $(\mathrm{OR}=2.4, \mathrm{p}=0.032)$. The results might be distorted by the low number of new buildings.

Rate of positive samples increased consistently with the number of storeys (KW, $\mathrm{p}=0.001$ ), but severe contamination was found in some of the lower buildings as well. Ground level and one-storey buildings very often belong to traditional multi-building hospital complexes dispersed over a large plot. The longer and more complex distribution systems might account for the observed difference in colonization rates: if the system is shared between more buildings, both the ratio of positive samples and the CFU counts were higher $(\mathrm{OR}=2.9, \mathrm{p}=$ $0.0001)$.

The source of drinking water may also influence colonisation as the initial microbial community is widely different in the various source waters. In the potable water samples from the hospitals' distribution system, deep-ground water derived water was the least likely to contain Legionella over the limit of detection. Rate of positive samples and Legionella counts were both significantly higher in bank filtered and carstic water derived potable water samples $(\mathrm{OR}=9.2$, $\mathrm{p}=0.004$ and $\mathrm{MW}, \mathrm{p}=0.01$, respectively). 
Table II. Characteristics of the building, water supply and distribution systems of the investigated hospitals. Data was collected by questionnaire survey and on-site investigation. Facilities that reported or not reported nosocomial legionellosis case(s) during the study period were confirmed. Rate of positive samples was calculated for the first sampling

\begin{tabular}{|c|c|c|c|c|}
\hline \multirow[b]{2}{*}{ Characteristic } & \multicolumn{3}{|c|}{ Frequency (\%) of buildings } & \multirow[b]{2}{*}{$\begin{array}{l}\text { Samples (positive } \\
\text { for Legionella/all) }\end{array}$} \\
\hline & $\begin{array}{c}\text { Reported } \\
\text { nosocomial } \\
\text { legionellosis }\end{array}$ & $\begin{array}{c}\text { Not reported } \\
\text { nosocomial } \\
\text { legionellosis }\end{array}$ & Total & \\
\hline \multicolumn{5}{|l|}{ Source water } \\
\hline Deep groundwater & & & & $31 / 63$ \\
\hline Public network & 0 & 2 & 2 & $30 / 43$ \\
\hline Private well & 3 & 0 & 3 & $1 / 20$ \\
\hline Karstic water & 3 & 0 & 3 & $21 / 33$ \\
\hline Bank filtration & 9 & 7 & 16 & $148 / 190$ \\
\hline \multicolumn{5}{|l|}{ Number of buildings } \\
\hline 1 building & 7 & 4 & 11 & $70 / 121$ \\
\hline More buildings & 8 & 5 & 13 & $130 / 165$ \\
\hline \multicolumn{5}{|l|}{ Age of the hospital building } \\
\hline Before 1949 & 6 & 3 & 9 & $71 / 105$ \\
\hline Between 1950 and 1979 & 4 & 4 & 8 & $47 / 75$ \\
\hline Between 1980 and 1999 & 2 & 2 & 4 & $41 / 54$ \\
\hline After 2000 & 3 & 0 & 3 & $40 / 48$ \\
\hline \multicolumn{5}{|l|}{ Bulding structure } \\
\hline Simple (one-wing) & 4 & 2 & 6 & $44 / 66$ \\
\hline Complex (multiple wings) & 11 & 7 & 18 & $154 / 220$ \\
\hline \multicolumn{5}{|l|}{ Number of floors } \\
\hline $0-1$ & 1 & 0 & 1 & $11 / 11$ \\
\hline $2-3$ & 2 & 0 & 2 & $9 / 23$ \\
\hline $4-6$ & 8 & 8 & 16 & $122 / 188$ \\
\hline$\geq 7$ & 4 & 1 & 5 & $58 / 64$ \\
\hline \multicolumn{5}{|l|}{ Production of domestic hot water } \\
\hline Centrally within the building & 7 & 7 & 14 & $106 / 163$ \\
\hline Centrally outside the building & 8 & 1 & 9 & $93 / 119$ \\
\hline \multicolumn{5}{|c|}{ Primer heat source for hot water production } \\
\hline Gas furnace on premises & 11 & 7 & 18 & $137 / 217$ \\
\hline Transported hot water or steam & 4 & 2 & 6 & $63 / 69$ \\
\hline
\end{tabular}


Table II. (cont.)

\begin{tabular}{|c|c|c|c|c|}
\hline \multirow[b]{2}{*}{ Characteristic } & \multicolumn{3}{|c|}{ Frequency $(\%)$ of buildings } & \multirow[b]{2}{*}{$\begin{array}{l}\text { Samples (positive } \\
\text { for Legionella/all) }\end{array}$} \\
\hline & $\begin{array}{c}\text { Reported } \\
\text { nosocomial } \\
\text { legionellosis }\end{array}$ & $\begin{array}{c}\text { Not reported } \\
\text { nosocomial } \\
\text { legionellosis }\end{array}$ & Total & \\
\hline \multicolumn{5}{|c|}{ Temperature-drop within the in-building water distribution system ( $1^{\text {st }}$ sampling) } \\
\hline$\leq 5^{\circ} \mathrm{C}$ & 2 & 3 & 5 & $16 / 16$ \\
\hline $6-10^{\circ} \mathrm{C}$ & 1 & 1 & 2 & $30 / 51$ \\
\hline$>10^{\circ} \mathrm{C}$ & 12 & 4 & 16 & $153 / 215$ \\
\hline \multicolumn{5}{|c|}{ Number of hot water storage tanks } \\
\hline 0 & 1 & 1 & 2 & $7 / 7$ \\
\hline 1 & 4 & 3 & 7 & $55 / 60$ \\
\hline$>1$ & 10 & 3 & 13 & $94 / 115$ \\
\hline \multicolumn{5}{|c|}{ Volume of stored hot water } \\
\hline$<2.5 \mathrm{~m}^{3}$ & 4 & 4 & 8 & $40 / 49$ \\
\hline$\geq 2.5 \mathrm{~m}^{3}$ & 10 & 2 & 12 & $109 / 126$ \\
\hline \multicolumn{5}{|c|}{ Position of hot water storage tanks } \\
\hline Vertical & 10 & 5 & 15 & $99 / 123$ \\
\hline Horizontal & 4 & 1 & 5 & $37 / 38$ \\
\hline \multicolumn{5}{|c|}{ Connetction of the hot water storage tanks } \\
\hline Linear & 3 & 1 & 4 & $22 / 39$ \\
\hline Parallel & 6 & 2 & 8 & $56 / 60$ \\
\hline \multicolumn{5}{|c|}{ Hot water temperature (number of samples, $1^{\text {st }}$ sampling) } \\
\hline$\leq 55^{\circ} \mathrm{C}$ & 119 & 82 & 201 & $150 / 201$ \\
\hline$>55^{\circ} \mathrm{C}$ & 4 & 5 & 9 & $1 / 9$ \\
\hline \multicolumn{5}{|c|}{ Hot water temperature (number of samples, $1^{\text {st }}$ sampling) } \\
\hline$\leq 50^{\circ} \mathrm{C}$ & 102 & 74 & 176 & $139 / 176$ \\
\hline$>50^{\circ} \mathrm{C}$ & 21 & 13 & 34 & $12 / 34$ \\
\hline \multicolumn{5}{|c|}{ Drinking water storage } \\
\hline Yes & 3 & 0 & 3 & $34 / 48$ \\
\hline No & 12 & 9 & 21 & $166 / 238$ \\
\hline
\end{tabular}


In the hot water samples, results were similar: highest Legionella counts were found in systems supplied by bank filtration, but karstic water derived hot water were not significantly different. CFU counts in the deep groundwater derived hot water samples $(n=63)$, however, were significantly lower than any of the other 2 groups $(\mathrm{OR}=3.2, \mathrm{p}=0.0001)$. Groundwater derived samples were divided further into public utility supplies and private wells, Legionella counts were significantly lower in the former group (MW p < 0.001).

The observed effect of source water was independent from water treatment, including the presence or absence of disinfection. Individual water treatment was not applied in any of the hospitals, but 19 were supplied by disinfected (chlorinated), and 4 by non-disinfected potable water. Legionella counts were significantly higher in the former (MW, $\mathrm{p}=0.0001)$.

Drinking water storage (present in 3 hospitals) did not increase the rate of positive samples or the observed CFU counts, neither when analysed as an independend factor or in combination with the source of the potable water. All investigated hospitals had centralized hot water production, produced either within the building, or outside, but within the premises (Table II). The latter was identified as higher risk for colonization $(\mathrm{OR}=2.0, \mathrm{p}=0.012)$. Primary heat source was gas furnace in 6 and hot water transported from an external heat plant in 17 hospitals. Though in both cases the hot water is produced through a heat exchanger (thus there is no contact between the primary water and the produced water), and the produced water temperature is not different, the latter resulted in significantly higher Legionella counts $(\mathrm{OR}=6.1, \mathrm{p}=0.0001)$. Hot water was stored in most distribution systems (92\%), this also increased the risk of Legionella colonization, especially in the case of more than one storage tanks or large stored volume (Table II). The position and the connection of the storage tank was also a statistically significant factor (horizontal, parallel tanks being the highest risk), however, due to the low number of cases in each group, the practical significance of this result is low (Table II).

Multivariate analysis of the risk factors

Significant factors (either in the rate of positivity or Legionella count) from the above analysis were included in multiple logistic regression analysis (Table III). Water temperature was confirmed to be the strongest determinant: Odds ratio was 58.3 for samples below $50{ }^{\circ} \mathrm{C}(\mathrm{p}=0.004)$. Though $55^{\circ} \mathrm{C}$ was shown to be even more protective against Legionella colonization, it was not included in the multivariate analysis due to the limited number of samples above this value. Hot water distribution systems shared between several buildings are also increased risk environments $(\mathrm{OR}=27.3, \mathrm{p}=0.042)$. Volume of the stored water and 
Table III. Predictive variables associated with Legionella spp. presence as determined by univariate and multiple logistic regressions. Variables from that were found significantly associated with the rate of positive samples or Legionella CFU counts in Mann-Whitney univariate logistic regression tests were included in the multivariate analysis

\begin{tabular}{lll}
\hline Characteristics & $\begin{array}{l}\text { Univariate regression } \\
\text { OR }(95 \% \mathrm{CI})\end{array}$ & $\begin{array}{l}\text { Multiple logistic } \\
\text { regression } \\
(95 \% \mathrm{CI})\end{array}$ \\
\hline $\begin{array}{l}\text { Source water other than groundwater } \\
\text { (karstic and bank filtered water) }\end{array}$ & $3.2(1.8-5.8)^{1}$ & $28.0(0.7-990.5)$ \\
Year of construction of the building $\geq 2000$ & $2.4(1.1-5.4)^{3}$ & $0.6(0.1-3.2)$ \\
More buildings sharing the hot water network & $2.9(1.7-4.9)^{1}$ & $27.3(1.1-659.5)^{3}$ \\
Complex building structure (multiple wings e.g.) & $1.0(0.6-1.9)$ & - \\
Temperature of the hot water samples: $<50^{\circ} \mathrm{C}$ & $6.9(3.1-15.2)^{1}$ & $58.3(3.7-927.3)^{2}$ \\
Temperature of the hot water samples: $<55^{\circ} \mathrm{C}^{*}$ & $23.5(2.9-192.7)^{2}$ & - \\
Hot water production outside of the building sampled & $2.0(1.2-3.5)^{3}$ & $0.4(0.0-9.4)$ \\
Production the primer heat energy: with district heating & $6.1(2.5-14.8)^{1}$ & $5.7(0.5-62.6)$ \\
Number of hot water storage tanks: $>1$ & $0.4(0.1-1.1)$ & - \\
Volume of the stored hot water $\geq 2.5 \mathrm{~m}^{3 * *}$ & $1.4(0.6-3.5)$ & $26.7(0.9-764.0)$ \\
\hline
\end{tabular}

${ }^{1} \mathrm{p}<0.001,{ }^{2} \mathrm{p}<0.005,{ }^{3} \mathrm{p}<0.05$

* Not included in the multivariate analysis because of the low sample number of samples over $55{ }^{\circ} \mathrm{C}$

**Included in the multivariate analysis because of the strong significant result by Mann-Whitney test

the source of drinking water (if derived from other source than deep groundwater) also increased the risk of colonization, however, the result was not statistically significant at a $95 \%$ confidence level $(\mathrm{OR}=26.7, \mathrm{p}=0.055$ and $\mathrm{OR}=28.0$, $\mathrm{p}=0.067$, respectively). According to the univariate analysis, newer buildings (built after 2000) were more likely to be colonized; this - evidently biased - correlation was no longer seen in the multivariate analysis. The type of the primary heat used for hot water production, which was also an unexpected influencing factor, as it is not directly in contact with the produced hot water, was not found to be significant when combined with other parameters.

\section{Effect of risk management interventions}

Most hospitals initiated risk management actions after the first unfavourable results. Interventions included one or more of the followings: increasing the hot water temperature, (single or regular) heat-shock disinfection, pipeline reconstruction or other engineering works, shock or continuous chemical disinfection or installation of point-of-use bacterium filters in the high risk wards (Table IV). 
Table IV. Efficiency of the risk management interventions. Risk management measures were usually performed after the first positive results (where applicable).

Efficiency was characterized as the rate of samples over the public health limit value

Code Risk management intervention Post-intervention samples
(above $1000 \mathrm{CFU} / \mathrm{L} / \mathrm{all}$ )

\begin{tabular}{|c|c|c|c|}
\hline 01 & & System regulation & $29 / 58$ \\
\hline 04 & & nd & nd \\
\hline 08 & & Regular heat-shock, system regulation & $3 / 19$ \\
\hline 14 & & nd & nd \\
\hline \multirow{2}{*}{16} & A & Heat-shock & $3 / 7$ \\
\hline & $\mathrm{B}$ & Heat-shock & $4 / 6$ \\
\hline 17 & & Heat-shock & $3 / 3$ \\
\hline 18 & & - & $0 / 2$ \\
\hline 19 & & Heat-shock & $5 / 5$ \\
\hline 22 & & Heat-shock & $0 / 13$ \\
\hline 27 & & Heat-shock & $18 / 61$ \\
\hline 28 & & Heat-shock & $5 / 9$ \\
\hline 30 & & In progress & \\
\hline 31 & & POU filters, elevated hot water temp. & $6 / 6$ \\
\hline 33 & & nd & nd \\
\hline 02 & & $\begin{array}{l}\text { Continuous disinfection } \\
\text { system regulation }\end{array}$ & $0 / 27$ \\
\hline 03 & & Chlorine-dioxid, system regulation & $0 / 10$ \\
\hline 05 & & Heat-shock & $0 / 4$ \\
\hline 06 & & nd & $6 / 7$ \\
\hline 09 & & nd & nd \\
\hline 10 & & nd & $4 / 34$ \\
\hline 11 & & nd & nd \\
\hline 13 & & nd & nd \\
\hline 26 & & nd & nd \\
\hline
\end{tabular}

nd: no data; POU: point-of-use 
a)

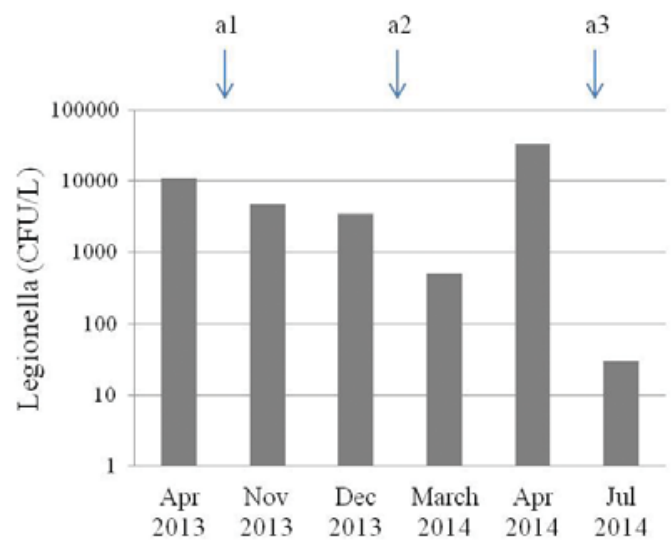

b)

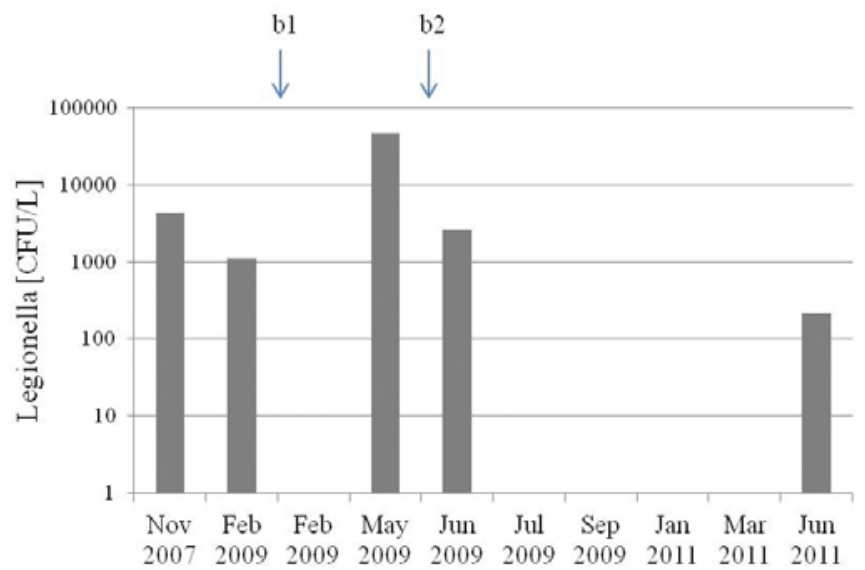

Figure 2. Efficiency of risk intervention measures in Hospital 28 (a) and Hospital 02 (b). Arrows indicate the time of interventions. In Hospital 28, heat shock disinfection was applied in October, 2013 (a1) and February, 2014 (a2). Hot water system was optimized and hot water temperature elevated subsequently (a3). In Hospital 02, chemical disinfection was used, first as a shock treatment (b1), then continuously (b2)

Overall effect of the interventions was clearly positive: hot water samples from the first sampling occasions in the investigated hospitals $(n=184)$ were more likely to be positive for Legionella, than the subsequent samples $(\mathrm{n}=294)$ (70\% vs 56\%; OR $1.8 \mathrm{p}=0.001)$, and Legionella counts were also higher (MW, $\mathrm{p}<0.001)$. Though the number of samples exceeding the public health limit value decreased by almost 40\%, still one third were over $1000 \mathrm{CFU} / \mathrm{L}$. Legionella counts in cold water samples from the first $(n=78)$ and subsequent samplings $(n=57)$ were not different $(M W, p=0.299)$. 
The median hot water temperature was elevated in 7 hospitals after the first sampling, though it only reached $50{ }^{\circ} \mathrm{C}$ in one (data not shown). The ratio of samples over 50 and $55{ }^{\circ} \mathrm{C}$ was doubled (from $16 \%$ to $33 \%$ and $4 \%$ to $9 \%$, respectively). Median temperature was unchanged $\left(44^{\circ} \mathrm{C}\right)$.

Heat-shock disinfection was reported by 8 hospitals (Table IV). Results indicated that the treatment was efficient in reducing the Legionella counts in the system, however, the effect was only temporary, if it was not repeated regularly (Figure 2a). One facility successfully applied first shock, then continuous chemical disinfection (Figure 2b). Both measures were only efficient if applied combined with system optimization.

The only unanimously effective method for the elimination of Legionella from the hot water at the tap was the application of point-of-use bacterium filters. Three hospitals introduced this intervention (one before and two after the first positive results). Only one of the samples from taps with filters $(n=55)$ contained Legionella $\left(3 \times 10^{4} \mathrm{CFU} / \mathrm{L}\right)$. This hospital used reusable filters which were not replaced and disinfected according to the manufacturer's instruction. After the correction of management practices, all subsequent samples were negative.

Comparison of hospitals reporting and not reporting nosocomial legionellosis

Fourteen hospitals reported presumptive or confirmed cases of nosocomial legionellosis during the study period, either before or after the first sampling. To assess the potential significant factors contributing to the infections, "reporting" and "non-reporting" hospitals were compared. In some cases the patients stayed in more than one hospitals during the latency period (2-14 days before the onset of the symptoms); all of these were considered "reporting" for the following analysis, regardless of the outcome of the epidemiological investigation. Both the rate of positive hot water samples ( $83 \%$ vs. $49 \%$ ), the number of samples over the public health limit value ( $60 \%$ vs. $36 \%)$ and the median Legionella count $\left(2.7 \times 10^{3}\right.$ vs. $0(<10) \mathrm{CFU} / \mathrm{L}, \mathrm{MW}, \mathrm{p}<0.001)$ were significantly higher in the reporting group. The hospitals reporting infections were colonized to a similar extent, while the colonization rates in the non-reporting group were diverse from none to severe: the highest median $\left(>10^{5} \mathrm{CFU} / \mathrm{L}\right)$ was observed in a facility that was not associated with a recognized infection. Legionella counts in the cold water samples were not different (median $0(<10) \mathrm{CFU} / \mathrm{L}$ for both groups, $\mathrm{MW}, \mathrm{p}=0.435$ ).

To assess the reasons behind the difference in the colonization, those environmental factors which were shown or assumed to affect the Legionella titers in the samples according to the previous analysis were compared. 


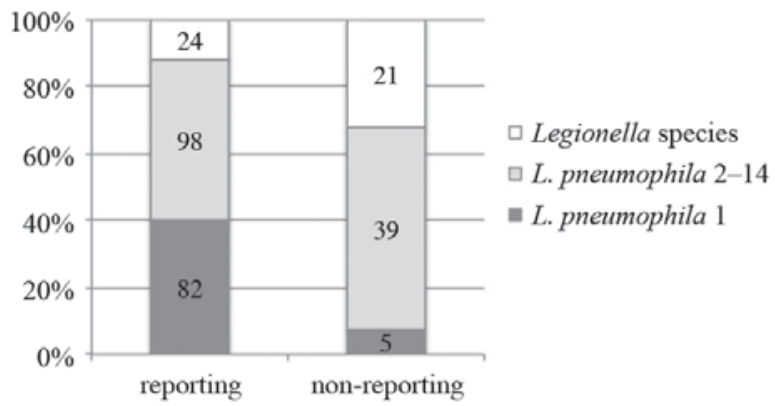

Figure 3. Serotype distribution of Legionella isolates from hospitals reporting and non-reporting nosocomial legionellosis incidents. Strains were isolated from hot and cold water samples from the hospitals' distribution system. Typing was performed by latex agglutination

Reporting and non-reporting hospitals did not separate by building characterstics. Most of the facilities were more than 30 years old in both groups. Interestingly, all three new hospitals (built after 2000) were associated with nosocomial infections. Size and complexity of the buildings, hot water production and storage were similar.

Of the parameters found to be significant or near significant in the multivariate analysis, hot water temperature was also comparable in the reporting and non-reporting hospitals (median $42.9{ }^{\circ} \mathrm{C}$ and $41.6{ }^{\circ} \mathrm{C}$, respectively, $\mathrm{MW} \mathrm{p}=$ 0.442 ). Source water distribution did not differ significantly ( $25 \%$ vs $18 \%$ of the samples originated from deep ground water). The proportion of facilities sharing the hot water distribution system with other buildings was also the same (55\% vs $62 \%$ ). The only parameter where difference was observed was the ratio of systems storing large volume of hot water $\left(>2.5 \mathrm{~m}^{3}\right)$, which was higher among the reporting hospitals ( $71 \%$ vs $33 \%)$.

The serotype distribution of the isolated Legionella strains, however, was fundamentally different $\left(\mathrm{Chi}^{2}\right.$ test, $\mathrm{p}<0.001$, Figure 3$)$. In the hospitals reporting nosocomial infections, $40 \%$ of the isolates were L. pneumophila sg 1 , while in the non-reporting hospitals only $8 \%$. This serotype, which is most often associated with human illness, was detected in $86 \%$ of the reporting and $56 \%$ of the nonreporting hospitals. This rate was $57 \%$ and $35 \%$ for L. pneumophila sg 2-14 and $14 \%$ and $19 \%$ for non-pneumophila species.

\section{Discussion}

Majority of the Hungarian hot water systems - including health care facilities - are operating without any awareness of Legionella risk or targeted risk 
management interventions. The high rate of positive samples is a clear consequence of this situation. The present prevalence rates are in the upper segment of the previously reported $12-90 \%$ [18, 29-35]. Most published surveillance studies from various geographic locations (Canada, Taiwan and USA) report 60-70\% colonization rates on similar sample size $[18,31,34]$. In the study where the rate was comparable to the current findings, the hospitals were not randomly selected [35].

The notification rate of health-care associated legionellosis cases was less than $1 /$ million inhabitants/year in the past years [9]. The observed colonization rates support the presumption that the actual incidence rate is severely underestimated. Diagnostic tests are not routinely directed towards legionellosis due to the low awareness of the disease and the absence of environmental monitoring.

Many hospitals offer favourable conditions for the proliferation of legionellae: majority of the facilities are either large, complex buildings, or very often follow the traditional "pavilion style" layout, with numerous buildings (built at various times, but dating often back to more than a century) dispersed over a large plot. The hot water distribution systems are therefore usually extensive, deteriorated, with oversized storage tanks. The large temperature difference in the systems indicated inefficient (or sometimes absent) recirculation, and the presence of low-flow or stagnant sections. The hot water temperature is generally intentionally low $\left(<45^{\circ} \mathrm{C}\right)$ for energy and cost efficiency and scalding prevention. None of the investigated hospitals met with the European recommendation of stored hot water temperature $>60^{\circ} \mathrm{C}$, a temperature drop $<5^{\circ} \mathrm{C}$, resulting in water temperatures $>55^{\circ} \mathrm{C}$ in the entire system [36]. Due to the low initial water temperatures, even the new and well-circulated systems are not sufficiently safe: the three newest $(<10$ years old at the time of the sampling) investigated hospitals were heavily colonized by L. pneumophila sg 1 , and all reported nosocomial legionellosis cases.

In all investigated hospitals the present survey was the first analysis for the presence of legionellae, as routine environmental surveillance does not extend to this parameter. The subsequent interventions - required by the public health authorities in the case of epidemiological investigation following nosocomial infection, and voluntary in the absence of recognized cases - generally failed to eradicate legionellae from the system, and significant reduction of the Legionella counts was only achieved after a number of combined measures. Heat-shock disinfection was the most frequently applied intervention, but the efficiency was generally low (1-2 log reducion), and only temporary if perfomed without other actions. Besides the cost and the difficulty of performing heatshock disinfection, a further obstacle is the poor mechanical condition of the older pipelines, resulting in frequent breakage. One facility successfully applied 
continuous chemical disinfection, though the first shock disinfection dramatically increased Legionella counts due to the disruption of the biofilm. Elevated hot water temperatures (at least $>50{ }^{\circ} \mathrm{C}$ in the entire system) also resulted in lower CFU counts. However, all of the above interventions were only successful when combined with inspection, adjustment and if necessary, reconstruction of the network to eliminate stagnant sections and optimize water circulation. Replacement of the pipelines is not efficient in itself, as generally the main pipes are left intact and as the present result shows, colonization can occur in a relatively short time.

All health-care facilities are elevated risk settings due to the high proportion of patients of compromised immunocompetence, however, some units (such as intensive care, haematology, solid organ transplant wards) are even more vulnerable. According to the present results, there is no significant difference between the critical and the other units. However, point-of-use filters were usually first introduced in the highest risk areas. This was found to be the most efficient and immediate preventive measure, if properly maintained and replaced.

In the hospitals associated with nosocomial infections, the hot water system of the facility was usually confirmed as the potential infective source. Both the Legionella counts and the prevalence of L. pneumophila sg 1 was higher compared to the hospitals selected randomly for study purposes. L. pneumophila sg 1 is generally considered the most virulent subtype responsible for the majority of the recognized infections. However, this association might be biased by the fact that the routinely applied clinical urinary tests only screen for L. pneumophila sg 1 antigens.

The current study could not identify the environmental factors influencing the above differences. Though a number of parameters were associated positively with the rate of samples containing Legionella or high CFU counts (such as a vulnerable drinking water source or the length and complexity of the hot water distribution system), none of them were different in the hospitals reporting legionellosis incidences, and the other facilities. Even the hot water temperature, which was confirmed to be the strongest driver of Legionella colonization, was similar in the two groups. Our hypothesis is that all investigated hospitals are at risk due to the unsatisfactory management practices, and often incidental factors such as the virulence of the colonizing strains influence the actual hazard.

The present study in accordance with previous results indicated that the hot water system of health-care facilities are important sources of nosocomial legionellosis infections $[32,37]$. However, the experience shows that the operators are still not aware of the associated risk, and the ad-hoc interventions following the positive samples are generally not sufficient for risk management. Based on the present outcomes, a regulatory recommendation was prepared to entail 
health-care facilities to carry out appropriate Legionella risk assessment and risk management including regular environmental monitoring.

\section{Conclusions}

Hungarian health-care facilities operate without awareness of Legionella risk associated with inappropriately managed hot water distribution system. The low water temperature - resulting partly from scalding prevention and energy efficiency considerations, partly from the insufficient circulation in the network leads to extremely high colonization rates, often above the internationally recognized public health intervention limit value. Other factors, such as vulnerable drinking water source and complex hot water distribution systems were shown to aggravate the hazard. While the age of the building is also a risk factor, without appropriate risk management practices even the new networks are rapidly colonized.

In those hospitals, where nosocomial legionellosis was reported, both Legionella counts and the prevalence of virulent subtypes were higher. However, the environmental factors contributing to this difference were not identified within this study. Targeted risk mitigation measures were usually inefficient in eradicating the colonization and significant reduction was only achieved where consistent long-term measures were taken.

The results call for the introduction of a national regulation to ensure regular Leginella monitoring, risk assessment and risk management in all health-care facilities in Hungary to raise awareness to a hitherto underestimated nosocomial risk and in the meanwhile reduce the number of actual infections.

\section{Acknowledgements}

This work was partially funded by the EU (GVOP-3.1.1-2004-05-0517/3.0). The authors would like to thank the staff of the Department of Water Hygiene at the National Public Health Center, Directoriat of Environmental Health, Budapest, Hungary and the staff of the hospitals where the research was done.

\section{References}

1. Muder, R. R., Yu, V. L., McClure, J. K., Kroboth, F. J., Kominos, S. D., Lumish, R. M.: Nosocomial legionnaires' disease uncovered in a prospective pneumonia study: Implications for underdiagnosis. JAMA 249, 3184-3188 (1983). 
2. National Center for Epidemiology (OEK): Hungarian Guideline on Legionnaires' Disease and its Prevention. Epinfo 14, (2007).

3. VROM. The Netherlands Ministry of Housing. Modelbeheersplan Legionellapreentie in Liedingwater Distribution No. 16827 (2002).

4. Legionnaires' Disease - A Guide for Employers. (http://www.hse.gov.uk/pubns/iacl27. pdf). London, United Kingdom: Health and Safety Executive (2004).

5. Ministère de la Sante et des Solidarités: L'eau dans les Établissements de Santé - Guide Technique, France (http://www.sante.gouv.fr/htm/dossiers/eau_etabs/accueil.htm). (2005).

6. Deutscher Verein des Gas- und Wasserfaches: Arbeitsblatt W 551. Trinkwassererwärmungs- und Leitungsanlagen; Technische Maßnahmen zur Verminderung des Legionellenwachstums; Planung, Errichtung, Betrieb und Sanierung von Trinkwasser-Installationen. Deutscher Verein des Gas- und Wasserfaches, Germany (2004).

7. Exner, M., Kramer, A., Lajoie, L., Gebel, J., Engelhart, S., Hartemann, P.: Prevention and control of health care-associated waterborne infections in health care facilities. Am J Infect Control 33, S26-S40 (2005).

8. Exner, M., Hartemann, P., Lajoie, L.: Health-care facilities. In Bartram, J., Chartier, Y., Lee, J. V., Pond, K., Surman-Lee, S. (eds): Legionella and the prevention of legionellosis, Edition. World Health Organization, Geneva, Switzerland, 2007, pp. 89-102.

9. ECDC: Legionnaires' disease in Europe, 2013, 1st Edition. European Centre for Disease Prevention and Control (ECDC), Stockholm, Sweden (2015).

10. García-Fulgueiras, A., Navarro, C., Fenoll, D., García, J., González-Diego, P., JiménezBuñuales, T., Rodriguez, M., Lopez, R., Pacheco, F., Ruiz, J., Segovia, M., Balandrón, B., Pelaz, C.: Legionnaires' disease outbreak in Murcia, Spain. Emerg Infect Dis 9, 915-921 (2003).

11. Fisher-Hoch, S. P., Bartlett, C. L., Tobin, J. O., Gillett, M. B., Nelson, A. M., Pritchard, J. E., Smith, M. G., Swann, R. A., Talbot, J. M., Thomas, J. A.: Investigation and control of an outbreaks of legionnaires' disease in a district general hospital. Lancet 1, 932-936 (1981).

12. Meenhorst, P. L., Reingold, A. L., Groothuis, D. G., Gorman, G. W., Wilkinson, H. W., McKinney, R. M., Feeley, J. C., Brenner, D. J., van Furth, R.: Water-related nosocomial pneumonia caused by Legionella pneumophila serogroups 1 and 10. J Infect Dis 152, 356-364 (1985).

13. Colville, A., Crowley, J., Dearden, D., Slack, R. C., Lee, J. V.: Outbreak of legionnaires' disease at University Hospital, Nottingham. Epidemiology, microbiology and control. Epidemiol Infect 110, 105-116 (1993).

14. Knirsch, C. A., Jakob, K., Schoonmaker, D., Kiehlbauch, J. A., Wong, S. J., Della-Latta, P., Whittier, S., Layton, M., Scully, B.: An outbreak of Legionella micdadei pneumonia in transplant patients: Evaluation, molecular epidemiology, and control. Am J Med 108, 290-295 (2000).

15. Berthelot, P., Grattard, F., Ros, A., Lucht, F., Pozzetto, B.: Nosocomial legionellosis outbreak over a three-year period: Investigation and control. Clin Microbiol Infect 4, 385391 (1998).

16. Visca, P., Goldoni, P., Luck, P. C., Helbig, J. H., Cattani, L., Giltri, G., Bramati, S., Castellani Pastoris, M.: Multiple types of Legionella pneumophila serogroup 6 in a hospital heated-water system associated with sporadic infections. J Clin Microbiol 37, 2189-2196 (1999). 
17. Campins, M., Ferrer, A., Callis, L., Pelaz, C., Cortes, P. J., Pinart, N., Vaque, J.: Nosocomial legionnaire's disease in a children's hospital. Pediatr Infect Dis J 19, 228-234 (2000).

18. Stout, J. E., Muder, R. R., Mietzner, S., Wagener, M. M., Perri, M. B., DeRoos, K., Goodrich, D., Arnold, W., Williamson, T., Ruark, O., Treadway, C., Eckstein, E. C., Marshall, D., Rafferty, M. E., Sarro, K., Page, J., Jenkins, R., Oda, G., Shimoda, K. J., Zervos, M. J., Bittner, M., Camhi, S. L., Panwalker, A. P., Donskey, C. J., Nguyen, M.-H., Holodniy, M., Yu, V. L., Group, L. S.: Role of environmental surveillance in determining the risk of hospital-acquired legionellosis: A national surveillance study with clinical correlations. Infect Control Hosp Epidemiol 28, 818-824 (2007).

19. Serrano-Suarez, A., Dellunde, J., Salvado, H., Cervero-Arago, S., Mendez, J., Canals, O., Blanco, S., Arcas, A., Araujo, R.: Microbial and physicochemical parameters associated with Legionella contamination in hot water recirculation systems. Environ Sci Pollut Res Int 20, 5534-5544 (2013).

20. Stout, J. E., Yu, V. L., Best, M. G.: Ecology of Legionella pneumophila within water distribution systems. Appl Environ Microbiol 49, 221-228 (1985).

21. Rogers, J., Dowsett, A. B., Dennis, P. J., Lee, J. V., Keevil, C. W.: Influence of temperature and plumbing material selection on biofilm formation and growth of Legionella pneumophila in a model potable water system containing complex microbial flora. Appl Environ Microbiol 60, 1585-1592 (1994).

22. Zacheus, O. M., Martikainen, P. J.: Occurrence of legionellae in hot water distribution systems of Finnish apartment buildings. Can J Microbiol 40, 993-999 (1994).

23. Straus, W. L., Plouffe, J. F., File, T. M., Jr., Lipman, H. B., Hackman, B. H., Salstrom, S. J., Benson, R. F., Breiman, R. F.: Risk factors for domestic acquisition of legionnaires disease. Ohio Legionnaires Disease Group. Arch Intern Med 156, 1685-1692 (1996).

24. Arnow, P. M., Chou, T., Weil, D., Shapiro, E. N., Kretzschmar, C.: Nosocomial legionnaires' disease caused by aerosolized tap water from respiratory devices. J Infect Dis 146, 460-467 (1982).

25. European Surveillance Scheme for Travel Associated Legionnaires' Disease and the European Working Group for Legionella Infections (EWGLI). European Guidelines for Control and Prevention of Travel Associated Legionnaires' Disease, http://www.ewgli. org/public_info/publicinfo_european_guidelines.asp, accessed 13 July 2005 (2005).

26. ISO 5667-5:2006. Water quality - Sampling - Part 5: Guidance on sampling of drinking water from treatment works and piped distribution systems. Geneva, Switzerland: International Standard Organization.

27. ISO 19458:2006. Water quality - Sampling for microbiological analysis. Geneva, Switzerland: International Standard Organization.

28. ISO 11731-2:2004. Water quality - Detection and enumeration of Legionella - Part 2: Direct membrane filtration method for waters with low bacterial counts. Geneva, Switzerland: International Standard Organization.

29. Liu, W. K., Healing, D. E., Yeomans, J. T., Elliott, T. S.: Monitoring of hospital water supplies for Legionella. J Hosp Infect 24, 1-9 (1993).

30. Patterson, W. J., Hay, J., Seal, D. V., McLuckie, J. C.: Colonization of transplant unit water supplies with Legionella and protozoa: Precautions required to reduce the risk of legionellosis. J Hosp Infect 37, 7-17 (1997).

31. Yu, P. Y., Lin, Y. E., Lin, W.-R., Shih, H.-Y., Chuang, Y.-C., Ben, R.-J., Huang, W.-K., Chen, Y.-S., Liu, Y.-C., Chang, F.-Y., Yen, M.-Y., Liu, C.-C., Ko, W.-C., Lin, H.-H., Shi, Z.-Y.: The high prevalence of Legionella pneumophila contamination in hospital potable 
water systems in Taiwan: Implications for hospital infection control in Asia. Int J Infect Dis 12, 416-420 (2008).

32. Sabria, M., Modol, J. M., Garcia-Nunez, M., Reynaga, E., Pedro-Botet, M. L., Sopena, N., Rey-Joly, C.: Environmental cultures and hospital-acquired legionnaires' disease: a 5-year prospective study in 20 hospitals in Catalonia, Spain. Infect Control Hosp Epidemiol 25, 1072-1076 (2004).

33. Marrie, T., Green, P., Burbridge, S., Bezanson, G., Neale, S., Hoffman, P. S., Haldane, D.: Legionellaceae in the potable water of Nova Scotia hospitals and Halifax residences. Epidemiol Infect 112, 143-150 (1994).

34. Alary, M., Joly, J. R.: Factors contributing to the contamination of hospital water distribution systems by legionellae. J Infect Dis 165, 565-569 (1992).

35. Kool, J. L., Bergmire-Sweat, D., Butler, J. C., Brown, E. W., Peabody, D. J., Massi, D. S., Carpenter, J. C., Pruckler, J. M., Benson, R. F., Fields, B. S.: Hospital characteristic associated with colonization of water system by Legionella and risk of nosocomial legionnaries' disease: A cohort study of 15 hospitals. Infect Control Hosp Epidemiol 20, 798805 (1999).

36. Members of the European Surveillance Scheme for Travel Associated Legionnaires' Disease (EWGLINET) and the European Working Group for Legionella Infections (EWGLI): European Guidelines for Control and Prevention of Travel Associated Legionnaires' Disease (2005).

37. Joly, J., Alary, M.: Occurrence of nosocomial Legionnaires' disease in hospitals with contaminated potable water supply. In Barbaree, J. M., Breiman, R. F., Dufour, A. P. (eds): Legionella: Current Status and Emerging Perspectives. American Society for Microbiology, Washington DC, USA, 1993, pp. 39-40. 